\title{
Antecedents and Consequences of Patient Satisfaction in the Context of Private Hospitalization Services
}

\author{
AHMAD AZMI M. ARIFFIN \\ NORZALITA A. AZIZ \\ Graduate School of Business \\ Universiti Kebangsaan Malaysia \\ 43600 UKM Bangi, Selangor \\ MALAYSIA \\ NORHAYATI M. ZAIN \\ BAMA V.V. MENON \\ KPJ Healthcare University College \\ 71800 Nilai, Negeri Sembilan \\ MALAYSIA
}

\begin{abstract}
This study aims to investigate the impacts of perceived quality and perceived value on patient satisfaction as well as the influence of patient satisfaction on hospital's brand image, patient loyalty and wordof-mouth intention in the context of private hospitalization services. With regards to the conceptualization of perceived quality, this study also attempts to uncover the underlying dimensions of hospitalization quality in the specific context of private hospital. This study surveyed 254 patients who were admitted for at least three days at private hospital in Malaysia, revealing that patient satisfaction with hospitalization services could be explained directly or indirectly by five hospitalization quality domains namely outcome quality, rights and privacy, medical quality, service quality, and servicescape. The findings of this study also show that patient satisfaction has significant impacts on all the three consequences variables - brand image, patient loyalty and WoM intention. The two major contributions of this study include the conceptualization of hospitalization quality domains and the newly developed measurement of perceived value in the context of profit-oriented healthcare institutions.
\end{abstract}

Key-Words: - Hospitalization quality, Patient satisfaction, Perceived value, Brand image, Patient Loyalty, Word-of-mouth intention

Received: June 13, 2021. Revised: November 25, 2021. Accepted: January 12, 2022. Published: January 14, 2022.

\section{Introduction}

As the healthcare industry is experiencing a swift transformation to meet evolving expectations, patient satisfaction is widely emphasized as the key indicator of healthcare quality [1]. However, health professionals are claimed to have scant understanding of patients' experiences and perceptions of satisfaction [2].

Review of previous literature indicates that most scholarly works on patient satisfaction focus on outpatient services, whereas studies on inpatient services mostly pertained to a specific illness rather than the admission experiences at large. Minimal systematic empirical evidence is currently available on the antecedents and consequences of patient satisfaction in the context of hospitalization experiences in privately owned hospital settings. The hospitalization services of exceptional quality also have crucial influence in promoting a hospital in the marketplace of medical tourism, which is a strategic aim of most private hospitals in the contemporary global healthcare industry [3].

In general, the public generally hold diverse levels of perception and expectation on the overall services offered by public versus private hospitals [4]. Given the different nature of the service provisions, studies focusing on inpatient experiences in private setting require a distinct set of quality measures that differ from those on publicly funded hospitals. This study attempts to address these gaps, proposing new measures of hospitalization quality in the private hospital setting. To the best knowledge of the authors, this study is also the first reference on the relationships between the domains of hospitalization quality and patient satisfaction as well as perceived value. 


\section{Literature Review}

Patient satisfaction is a multidimensional construct pertaining to patient perceptions and attitudes that are developed regarding the overall healthcare experience[1]. Past studies have provided compelling evidence of the direct relationship between perceived service quality and patient satisfaction [5,6,7]. However, most of these studies examined outpatient service settings. This present study aims to fill this void by focusing on hospitalization quality. It is important to note that quality is always linked to institutional effectiveness [8].

As previously described, most existing studies on patient satisfaction employed a widely used marketing instrument called the Servqual $[9,10]$ or modified versions, such as the Privhealthqual scale [11] or Servperf [11]. Such prespecified instruments are insufficient for measuring the holistic perspective of perceived quality in hospital settings [13]as patient and customer are fundamentally dissimilar concepts [2].

Based on an extensive review of literature in healthcare, [13] proposed the dimensionality of hospital service quality called the 6-Q framework: technical quality, infrastructural quality, interactional quality, procedural quality, personnel quality, and social support quality. However, the authors clearly noted that the framework is applicable only to tertiary healthcare establishments that focus on advanced investigation and specialized treatment. While a lot of studies have investigated the determinants and consequences of patient satisfaction, the results remain inconclusive and, in some cases, contradictory [14].

[15] Strongly argued that any customer satisfaction index should measure both satisfaction and its determinants, consequences, and the relationships among these variables in a single model based on a specific service context. Referencing this principle, patient satisfaction is conceptualized in this study based on the wellestablished national Customer Satisfaction Index Model that represents a cumulative evaluation of hospitals' service offering (hospitalization), as opposed to patients' evaluation of a specific transaction [16]. Despite its rigor and utility, no scholarly study has been found employing the national satisfaction index model to investigate hospitalization experience in the context of private hospitals.

The first national customer satisfaction index was the Swedish Customer Satisfaction Barometer developed by [17]. The American Customer
Satisfaction Index (ACSI) was launched in 1994 [16], followed by the Swiss Index of Customer Satisfaction in 1997, and then the European Customer Satisfaction Index in 1999. The widely used ACSI model links customer satisfaction to its antecedents, namely, perceived quality, customer expectations, and perceived value, as well as consequences, identified as customer loyalty and customer complaints. The results of all these customer satisfaction indices cannot be directly compared, as the structure and indicators used differ.

The Malaysian Customer Satisfaction Index Model (MCSI) was proposed by [18], representing customers' evaluation of the quality of the service provided by organizations in Malaysia. The MCSI incorporates product/service image as a consequence variable of satisfaction in place of the ACSI's customer complaint variable.

\section{Patient Satisfaction}

Based on the ACSI as well as MCSI, Patient satisfaction is posited to be determined by two antecedents namely:

1. Hospitalization quality: Patient's evaluation of their hospitalization experience starting from admission until discharged [3].

2. Perceived value: Overall perceived benefits obtained by the patient relative to the costs incurred, length of stay as well as perceived ulterior motive [19].

As previously noted, the impact of perceived quality on patient satisfaction is unquestionably critical. According to [20], private healthcare institutions have been accused of being overly concerned with generating profit objectives instead of offering quality medical services at reasonable prices. Thus, the construct of perceived value in this study is operationalized partly based on the effect of perceived ulterior motive.

Because of the intense competition in the private healthcare industry, unlike nonprofit-oriented healthcare institutions, private hospitals must cultivate a stronger base of loyal patients to ensure long-term survival [19]. Loyalty is undeniably a vital business success factor that can only be developed and sustained through the provision of excellent service quality and continuous improvement in satisfaction levels [4]. The proposed model also considers the effect of hospitals' brand image as it is considered as one of the most powerful factors considered by patients when selecting a hospital for medical treatment [21]. 
Apart from loyalty and brand image, [22] contended that word-of-mouth (WoM) also acts as the most vital acquisition channel in the profit-based healthcare industry particularly through socialmedia platforms. However, there remains a dearth of knowledge available regarding the determinants of WoM in the healthcare industry. The extant of literature indicates that none of the existing related models appears to have simultaneously addressed all the following three outcome variables for predicting patient satisfaction in a single model:

1. Hospital's brand image - The set of associations attached to the hospital as a brand in patient memory [23,24].

2. Patient loyalty - The tendency of a patient to recognize and repeatedly choose the same medical service provider or hospital [3].

3. Word-of-mouth intention - The patient attitude towards giving favourable word-of-mouth referrals to others [25].

Theoretically, the indicators of hospitalization quality as well as perceived value as the determinants of patient satisfaction in the context of private hospitals should differ from those of outpatient services and public hospitals. The attempt to address this notable methodological gap is another main contribution of this study. Thus, the main objectives of this study are twofold:

1. To examine the relative explanatory power of hospitalization quality as well as perceived value on patient satisfaction in the context of private hospitals.

2. To determine the impacts patient satisfaction on patient loyalty, hospitals' brand image, and WoM intention.

\section{Methodology}

The unit of analysis of this study is individual patient of private hospital in Malaysia who are at least 18 years old and experienced hospitalization for at least three days in the year 2020. Formal permission and ethical clearance were obtained to get the required information from the database of patient's basic profiles maintained by the related health authority. Based on purposive sampling, a total of 411 ex-patients qualified as respondents. Of these 411 ex-patients, only 254 agreed to participate.

A structured questionnaire was used as the main instrument, and because of the pandemic, the most suitable method for distribution was web-based. With close follow-up, all 254 respondents returned the questionnaires. From these 254 respondents, only 242 were found to be appropriate for further analyses; the remainder were discarded mainly due to issues of extensively missing values and outlier status. Considering the difficulty of obtaining a large sample size in healthcare-related studies and the pandemic outbreak situation, 242 is regarded as satisfactorily sufficient. A recent related study by [26] also employed less than 200 patients as their respondents.

Based on [27], the hospitalization quality domains were treated as formative measurements as their indicators are assumed to cause the respective constructs. The measures for hospitalization quality were developed based on various sources, including the CAHPS Adult Hospital Survey, Picker's eight domains of Person-Centered Care, MSQH and JCI accreditation standards. [28] strongly advocated that the measures of hospitalization quality be developed using a mixed method of quantitative and qualitative inquiry. The qualitative technique requires patients to openly describe their admission experiences through in-depth interviews. The interviews with 14 respondents combined with a review of literature managed to generate a total of 47 measurement items.

Three subject matter experts were appointed to assess the content validity of the measurements. A total of 15 items were removed, leaving 32 items for further analysis. The thematic analysis of the remaining 32 items produced five distinct hospitalization quality domains labelled as:

1. Medical quality: "What" the patient actually receives from the healthcare services to solve their illness [29].

2. Service quality: "How" the healthcare service is delivered to the patients [29].

3. Outcome quality: Overall subjective evaluation of the outcome of the treatments and recovery status [30].

4. Servicescape: Physical environment including tangible elements of the hospital [31].

5. Right and privacy: Protection of patient's privacy and right including the involvement in the decision-making process [32].

Hospitalization requires patients to stay longer in the hospital setting and involves more interactions with hospital staff compared to outpatient services. It requires the provisions of accommodation and meals, in addition to extended clinical treatments. Thus, the domain of the physical environment of the hospital (servicescape) and, patients' rights and privacy should be singled out as separate domains. These two domains are also particularly distinctive to the context of private 
hospital as the patients culturally expect a hospitals' physical environment to be a hotel-like setting and are granted more rights or freedom in determining the manner in which their stay and treatments should be rendered.

Assessment of the properties of the formative measurement model indicated that no collinearity issue was detected, as the VIF for each relationship among the five domains was less than 10 (Hair et al., 2021). To further purify the quality domains, an indicator is to be retained only if its outer loading is above 0.5 . Based on this procedure, the finalized scale consists of 20 items.

Perceived value was measured using one item borrowed from [16] and two newly developed items generated from in-depth interviews. The perceived value of private hospitalization services should also be partly reflected in the ratings of the benefits given the required length of hospital stay, as well as the perception of whether ulterior profit motive is involved in service provision. These additional measurement items reflect the contextual phenomenon of a private healthcare business model, thus offering a more inclusive measure of perceived value as the key methodological contributions of this study.

Three measures of patient satisfaction with hospitalization experience were also based on the work of [16] representing overall satisfaction, disconfirmation of expectation and ideal experience. Patient loyalty was operationalized using two items adapted from [33]. Three items adapted from [34] were used to measure the hospital's brand image, reflecting the hospital's reputation, image, and sincerity. Finally, two items were borrowed from [35] to operationalize WoM intention, gauging the extent to which patients would recommend the hospital. The PLS-SEM using the Smart-PLS software was utilized for assessment of the measurement and structural model.

\section{Findings}

\subsection{Measurement Model of PLS-SEM}

The measurement model possess high internal reliability as the values of Cronbach alpha and composite reliability for the constructs were all greater than the recommended value of 0.7 [36] Convergent validity was also achieved as the values of all outer loadings and AVE were above 0.5 [36]. The Fornell-Larker criterion employed indicated that there was sufficient discriminant validity as the square roots of AVE were higher than the correlations for all constructs.

Table 1. Reliability and Convergent Validity

\begin{tabular}{|c|c|c|c|c|}
\hline Variables & $\begin{array}{c}\text { Outer } \\
\text { Loading }\end{array}$ & $\begin{array}{c}\text { Cronbach } \\
\text { Alpha }\end{array}$ & CR & AVE \\
\hline Perceived Value & & 0.729 & 0.874 & 0.674 \\
\hline Price-benefits & 0.822 & & & \\
\hline $\begin{array}{l}\text { Benefits-length of } \\
\text { stay }\end{array}$ & 0.808 & & & \\
\hline $\begin{array}{l}\text { Perceived ulterior } \\
\text { motive }\end{array}$ & 0.834 & & & \\
\hline Patient & & 0.740 & 0.890 & 0.659 \\
\hline Satisfaction & & & & \\
\hline Overall satisfaction & 0.871 & & & \\
\hline $\begin{array}{l}\text { Fulfilled } \\
\text { expectations }\end{array}$ & 0.846 & & & \\
\hline Ideals & 0.78 & & & \\
\hline Patient Loyalty & & 0.844 & 0.922 & 0.878 \\
\hline $\begin{array}{l}\text { Return to the same } \\
\text { hospital }\end{array}$ & 0.934 & & & \\
\hline $\begin{array}{l}\text { Choose the same } \\
\text { hospital }\end{array}$ & 0.940 & & & \\
\hline Word of mouth & & 0.820 & 0.911 & 0.858 \\
\hline $\begin{array}{l}\text { Recommend the } \\
\text { hospital }\end{array}$ & 0.916 & & & \\
\hline $\begin{array}{l}\text { Talk positively of } \\
\text { services }\end{array}$ & 0.936 & & & \\
\hline Brand Image & & 0.868 & 0.932 & 0.805 \\
\hline Reputation & 0.871 & & & \\
\hline Positive image & 0.911 & & & \\
\hline Sincerity & 0.909 & & & \\
\hline
\end{tabular}

\subsection{Structural Model of PLS-SEM}

The R2 represents the quantity of variance in the endogenous constructs, which is explained by all of the exogenous constructs. The values of $0.75,0.50$ and 0.25 represent substantial, moderate and weak effect size respectively [27]. The results presented in Table 2 showed the values represented mostly moderate effect sizes with exception of patient satisfaction.

The results revealed that 78 percent of the observed variation can be explained by the five hospitalization quality domains together with perceived value. The F2 is utilized to examine the relative impact of a predictor construct on an endogenous construct [37]. The values of $0.35,0.15$, and 0.02 represent large, medium, and small effect sizes respectively. Table 2 indicated that most of the effects were in the medium range. The results also showed that predictive relevance had been attained for all variables as the Q2 value were greater than zero [36]. 
Table 2. Structural Properties

\begin{tabular}{|c|c|c|c|c|}
\hline $\begin{array}{l}\text { Endogenous } \\
\text { Variables }\end{array}$ & $\begin{array}{l}\text { Predictive } \\
\text { Constructs }\end{array}$ & $\overline{\mathbf{R}^{2}}$ & $F^{2}$ & $\overline{\mathbf{Q}^{2}}$ \\
\hline $\begin{array}{l}\text { Perceived } \\
\text { Value }\end{array}$ & $\begin{array}{l}\text { Outcome } \\
\text { quality } \\
\text { Rights and } \\
\text { Privacy } \\
\text { Medical Quality } \\
\text { Service Quality } \\
\text { Servicescape }\end{array}$ & 0.68 & $\begin{array}{l}0.168 \\
0.173 \\
0.150\end{array}$ & 0.468 \\
\hline $\begin{array}{l}\text { Patient } \\
\text { Satisfaction }\end{array}$ & $\begin{array}{l}\text { Outcome } \\
\text { Quality } \\
\text { Rights and } \\
\text { Privacy } \\
\text { Medical Quality } \\
\text { Service Quality } \\
\text { Servicescape } \\
\text { Perceived Value }\end{array}$ & 0.78 & $\begin{array}{l}0.283 \\
0.271 \\
\\
0.246 \\
0.187 \\
0.007 \\
0.266\end{array}$ & 0.628 \\
\hline $\begin{array}{l}\text { Patient } \\
\text { Loyalty }\end{array}$ & $\begin{array}{l}\text { Brand Image } \\
\text { Patient } \\
\text { Satisfaction }\end{array}$ & 0.60 & $\begin{array}{l}0.068 \\
0.389\end{array}$ & 0.524 \\
\hline $\begin{array}{l}\text { WoM } \\
\text { Intention }\end{array}$ & $\begin{array}{l}\text { Brand Image } \\
\text { Patient } \\
\text { Satisfaction }\end{array}$ & 0.66 & $\begin{array}{l}0.299 \\
0.242\end{array}$ & 0.572 \\
\hline Brand Image & $\begin{array}{l}\text { Patient } \\
\text { Satisfaction }\end{array}$ & 0.54 & 0.381 & 0.437 \\
\hline
\end{tabular}

\subsection{Path Analysis}

The results of path analysis summarized in Table 3 showed that with the exception of servicescape, all the hospitalization quality domains including perceived value have strong significant impacts on patient satisfaction. Unsurprisingly, outcome quality appeared to have the greatest influence on patient satisfaction followed by right and privacy, perceived value, medical quality and service quality. In the case of the prediction of perceived value, all hospitalization quality domains with exception of right and privacy were found to be significantly related. The results showed that service quality had the greatest effect on perceived value followed by medical quality, outcome quality and servicescape. The results of the path analyses also provide strong empirical evidences to support the positive impacts of patient satisfaction on all the three proposed outcome variables. Patient satisfaction had the greatest impact on the hospital's brand image followed by patient loyalty and word-of-mouth intention.
Table 3. Path Coefficients

\begin{tabular}{lcccc}
\hline \multicolumn{1}{c}{ Relationship } & B & S.E & $\begin{array}{c}\text { P } \\
\text { value }\end{array}$ & Result \\
\hline $\begin{array}{l}\text { DV: Patient } \\
\text { Satisfaction }\end{array}$ & & & & \\
Outcome Quality & 0.324 & 0.076 & 0.000 & $S$ \\
Rights and Privacy & 0.280 & 0.08 & 0.000 & $S$ \\
Medical Quality & 0.221 & 0.055 & 0.000 & $S$ \\
Service Quality & 0.201 & 0.042 & 0.04 & $S$ \\
Servicescape & 0.077 & 0.107 & 0.171 & $N S$ \\
Perceived Value & 0.278 & 0.056 & 0.000 & $S$ \\
DV: Perceived & & & & \\
Value & & & & \\
Outcome Quality & 0.268 & 0.056 & 0.001 & $S$ \\
Rights and Privacy & 0.090 & 0.074 & 0.131 & $\boldsymbol{N} S$ \\
Medical Quality & 0.271 & 0.053 & 0.000 & $S$ \\
Service Quality & 0.288 & 0.078 & 0.000 & $S$ \\
Servicescape & 0.133 & 0.065 & 0.001 & $S$ \\
IV: Patient & & & & \\
Satisfaction & & & & \\
Brand Image & 0.739 & 0.036 & 0.000 & $S$ \\
Patient Loyalty & 0.572 & 0.058 & 0.000 & $S$ \\
WoM Intention & 0.413 & 0.049 & 0.000 & $S$ \\
\hline S: Supported,NS:Not Supported & & &
\end{tabular}

S: Supported, NS:Not Supported

\section{Discussions and Implications}

\subsection{Impacts of Hospitalization Quality on Patient Satisfaction}

The outcome quality appears to be the most influential quality domain affecting the extent to which patients are satisfied with hospitalization experiences in the private hospital setting, followed by rights and privacy, medical quality, and service quality. Notably, this study reveals servicescape which is associated with environmental quality to have an insignificant relationship with patient satisfaction. Nevertheless, the results indicate that the servicescape domain may influence patient satisfaction via perceived value.

Unquestionably, the attainment of desirable medical outcome quality is the core purpose of an entire hospitalization experience. It is the result that patients seek to obtain from the treatment received throughout their hospital stay. The outcome of clinical treatment depends on various factors that are both controllable and uncontrollable. The 
competencies of the medical team, medication prescribed, nursing care, and clinical facilities are among the factors. Outcome quality also depends on the roles the patients and their caregivers play in maintaining a patient's health following discharge. Effective discharge planning can avoid patient readmission, as well as aiding recovery by ensuring that medications are prescribed and correctly given.

"Rights and privacy" is the second most important domain in predicting patient satisfaction. In the private hospital setting, patients expect to be actively involved in most of the decisions regarding their healthcare. However, patients are comfortable with physicians' making decisions on their behalf, as long as the options and implications are clearly explained [38]. Shared decision-making requires doctors and patients to discuss the best available treatment options and patients are assisted in considering options to determine informed preferences. In addition to prioritizing the patients' rights at all times, patients' privacy must also be protected in an ethical and professional manner. Rights and privacy are one of the distinguishing factors that differentiate private hospitals from public hospital counterparts.

The third most effective predictor of patient satisfaction is medical quality. Medical quality refers to the ability of a hospital to attain high standards of patient health through clinical treatments, ultimately generating positive physiological and physical effects [29]. Medical quality is a core enabler of outcome quality, but in many cases, the clinical outcome of a treatment is not immediately detectable; thus, patients will normally evaluate it based on available tangible cues such as the doctors' expertise and the proper use of diagnostic equipment. Finally, patient satisfaction with hospitalization services is also significantly influenced by the service quality domain. Unlike medical quality that focuses on "what," service quality fundamentally reflects the "how" of service provision involved. Service quality domain is highly related to staffs' communication and interpersonal skills, including personal manners, responsiveness, and professionalism. It also involves the timeliness of treatment and the efficiency of admission and discharge processes. This quality domain can be a competitive advantage for hospitals to compete in the global health tourism marketplace. While physicians can be hired and equipment can be procured, personalities and processes are not easily imitated by the competitors.

Unexpectedly, this study found no empirical evidence to support a direct relationship between patient satisfaction and servicescape. Patients generally do not equate the direct impacts of the servicescape with the core purpose of hospitalization, which is centered on health improvement. The clinical equipment used might not be the most advanced, and there may not be luxury furnishings in patients' rooms, but the ultimate goal of health recovery may occur. In addition, compared to all other quality domains discussed earlier, patients generally already have some ideas of the hospital servicescape via some media exposures prior to admission. Although the servicescape was shown to have no direct impact on patient satisfaction, it does have a considerable influence on the service value of the hospitalization experience and should therefore not be ignored.

\subsection{Impacts of Hospitalization Quality on Perceived Value}

The findings of this study reveal that service quality is the most influential hospitalization quality domain for explaining perceived value, followed closely by the medical quality domain. The service quality domain, centered on how service is rendered, is closely connected to the perceptions of ulterior profit motives, whereas the medical quality domain is linked with both the cost of hospitalization and duration of stay. Patients do not have adequate clinical knowledge on the extent the treatments they received actually affect their recovery or whether ulterior profit motive is involved. The trustworthiness of the hospital in providing the best hospitalization experience at the most ideal cost is partly assessed by the patients by considering how they are personally treated by the staffs.

Medical quality is partly judged based on the treatments received as well as medical team competencies. Obviously, these elements are closely related to patients' cost to enjoy such privileges. Since not all treatments are covered by employers or insurance, patients still need to be selective in deciding the necessary treatments. Thus, hospitals that offer good (quality) choices of physicians and treatments (quantity) are regarded as providing favorable service value and thus manage to attract more patients. Although the results indicate that outcome quality is the third most powerful determinant of perceived value, the coefficient and corresponding significance level are substantial and only slightly lower than those of medical quality. Outcome quality is the direct measure of the desired health restoration and is indirectly influenced by perceived medical quality. While outcome quality is evaluated upon discharge, the notion of perceived value involves continuous assessment of the entire service process, starting from admission. This 
disproportion might explain why outcome quality demonstrates lower prediction power on perceived value compared with service and medical quality, despite its fundamental influence on patient satisfaction.

Despite no relationship being found regarding patient satisfaction, the servicescape is found to have a significant impact on perceived value. As perceived value is evaluated as a continuous assessment, the more favorable the tangibles aspects of the hospital, the higher the perceived service value of the overall hospitalization experience. Using up-to-date clinical equipment could help enhance patient perceptions of the service value although it might not necessarily result in the expected significant health improvement. The food served and the entertainment offered obviously have nothing much to do with the health outcome quality but might have strong impacts on the perceived value of the hospitalization service. Interestingly, no evidence is available to support the influence of rights and privacy on perceived value. Perceived value essentially refers to the benefits patients gain throughout the hospitalization experience. The rights and privacy domain, referring to the involvement of patients in decision-making, and the extent to which patients' rights and privacy are protected are fundamentally related to the performance of a process rather than the resulting benefits to be attained by patients.

\subsection{Impacts of Patient Satisfaction on Hospital's Brand Image, Loyalty, and WoM Intention}

This study demonstrated that patient satisfaction has the strongest impact on hospital image. Hospitals that managed to satisfactorily fulfill patients' expectations will be regarded as having a good reputation or image. Reputation is indeed an imperative for long-term survival in the healthcare industry, as the offerings are intangible in nature and highly dependent on trust. More importantly, hospitals with a positive brand image are also preferred and given priority, particularly by new patients. Interestingly, higher satisfaction will also lead to the perception that the hospital is sincere in its efforts to treat patients. This is critical for managing accusations and perceptions that the services offered by private hospitals usually involve ulterior profit motive.

The findings of this study also support the strong relationship between customer satisfaction and customer loyalty. The more satisfied the patients with the hospital experience, the more likely they will return for any future healthcare treatments needed. Finally, patient satisfaction is also found to significantly affect WoM marketing. Those who are impressed by the level of service offered by a hospital will be more likely to recommend the hospital to other people. Literature has demonstrated personal referral to be one of the most influential promotional strategies for healthcare services [19]. The importance of WoM marketing in today's digital world is increasing, as patients tend to share their hospitalization experiences on social media platforms, which are accessible to people across the globe.

\section{Suggestions for Future Research and Conclusions}

Hospital management amid contemporary industry competition must focus on patient satisfaction with hospitalization services in an effort to maximize patient loyalty, hospital's brand image, and patients' referral intention. Exceptional hospitalization experience quality has a crucial influence on promoting a hospital in the medical tourism marketplace.

The findings of this study yielded actionable results that can be used by hospital management to address areas or service processes demanding improvement. Except for the servicescape, all the hospitalization quality domains are found to have strong direct impacts on patient satisfaction, while the servicescape was shown to indirectly influence patient satisfaction via perceived value. The results also provide strong empirical evidence regarding the impacts of patient satisfaction on brand image, loyalty, and WoM intention.

Patients who are extremely dissatisfied with a hospital service will be more likely to lodge a complaint [19]; thus, a hospital should have a good system for handling complaints to minimize the potentially negative impacts on patient loyalty, hospital's image, and WoM intention. Given the highly competitive healthcare industry, patient satisfaction should not be treated as the ultimate aim, as patients can apparently be satisfied with more than one hospital. Thus, future studies should also consider investigating the influence of hospital brand attachment as a mediator between patient satisfaction and loyalty, as the construct of brand attachment represents emotional bonding that deeply connects patients with a particular hospital [39]. Different types of illnesses require different hospitalization services and therefore, offer different experiences to the patients. Finally, it is 
recommended that future studies on hospitalization should incorporate types of illnesses as one of the segmentation variables as well as patients from different types of private hospitals to provide a more meaningful interpretation of the findings.

\section{References:}

[1] Asamrew, N., Endris, A. A., \& Tadesse, M. Level of patient satisfaction with inpatient services and its determinants: A study of a specialized hospital in Ethiopia. Journal of Environmental and Public Health, 2020, pp. $1-12$.

[2] Afrashtehfar, K. I., Assery, M. K., \& Bryant, S. R. Patient Satisfaction in Medicine and Dentistry. International Journal of Dentistry, 2020. pp. 1-10.

[3] Habibi, A., \& Ariffin, A. A. M. Value as a medical tourism driver interacted by experience quality. Anatolia, Vol.30, No.(1), 2019, pp.35-46.

[4] Fatima, T., Malik, S. A., \& Shabbir, A. Hospital healthcare service quality, patient satisfaction and loyalty: An investigation in context of private healthcare systems. International Journal of Quality \& Reliability Management. Vol.35, No.6, 2018. pp. 1195-1214.

[5] Padma, P., Rajendran, C., \& Lokachari, P. S. Service quality and its impact on customer satisfaction in Indian hospitals: Perspectives of patients and their attendants. Benchmarking: An International Journal. 2010.

[6] Dagger, T. S., Sweeney, J. C., \& Johnson, L. W. A hierarchical model of health service quality: scale development and investigation of an integrated model. Journal of service research, Vol.10, No.2, 2007, pp.123-142.

[7] Vinagre, M. H., \& Neves, J. The influence of service quality and patients' emotions on satisfaction. International Journal of Health Care Quality Assurance. 2008.

[8] Miranda, R.D. \& Reyes-Chua, E. Best Practices in Quality Assurance in Selected Higher Education Institutions (HEIs) in the Philippines in the Light of the Malcom Baldrige Framework. WSEAS Transactions on Environment and Development, Vol.17, 2021, pp.533-545.

[9] Mohammadi-Sardo, M. R., \& Salehi, S. Emergency department patient satisfaction assessment using modified servqual model; a cross-sectional study. Advanced Journal of Emergency Medicine, Vol.3, No.1, 2019.

[10] Rahim, A. I., Ibrahim, M. I., Musa, K. I., \& Chua, S. L. Facebook Reviews as a Supplemental Tool for Hospital Patient Satisfaction and Its Relationship with Hospital Accreditation in Malaysia. International Journal of Environmental Research and Public Health, Vol.18, No.14, 2021. pp. 7454.

[11] Roshnee, F.R. The relative importance of service dimensions in a healthcare setting, International Journal of Health Care Quality Assurance, Vol. 21 No. 1, 2008. pp. 104-124, https:// doi.org/ 10.1108/ 09526860810841192

[12] Akdere, M., Top, M., \& Tekingündüz, S. Examining patient perceptions of service quality in Turkish hospitals: The SERVPERF model. Total Quality Management \& Business Excellence, Vol.31, No.3-4, 2020. 342-352.

[13] Swain, S., \& Kar, N. C. Hospital service quality as antecedent of patient satisfaction a conceptual framework. International Journal of Pharmaceutical and Healthcare Marketing. 2018.

[14] Batbaatar, E., Dorjdagva, J., Luvsannyam, A., Savino, M. M., \& Amenta, P. Determinants of patient satisfaction: a systematic review. Perspectives in Public Health, Vol.137, No.2, 2017. pp. 89-101.

[15] Bruhn, M., \& Grund, M. A. Theory, development and implementation of national customer satisfaction indices: the Swiss Index of Customer Satisfaction (SWICS). Total Quality Management, Vol.11, No.7, 2000. pp.1017-1028.

[16] Fornell, C., Johnson, M. D., Anderson, E. W., Cha, J., \& Bryant, B. E. The American customer satisfaction index: nature, purpose, and findings. Journal of Marketing, Vol.60, No.4, 1996. pp.7-18.

[17] Fornell, C. A national customer satisfaction barometer: The Swedish experience. Journal of marketing, Vol.56, No.1, 1992. pp. 6-21.

[18] Abdullah, M., Husain, N. \& El-Nassir, A.D. Theory and Development of National Customer Satisfaction Index: The Malaysian Index of Customer Satisfaction. The $6^{\text {th }}$ TQM World Congress. Saint Petersburg, Russia. 2001

[19] Habibi, A., Mousavi, M., Jamali, S. M., \& Ale Ebrahim, N. A bibliometric study of medical tourism. Anatolia, 2021, pp. 1-11. 
[20] The Star Online. Probe into overcharging complaints in private hospitals. 2012. Accessed 6 April 2016.

[21] Hu, H. Y., Chiu, S. I., Cheng, C. C., \& Hsieh, Y. F. A study on investigating patient satisfaction of medical centers using Taiwan customer satisfaction index in Taiwan. African Journal of Business Management, Vol.4, No.14, 2010. pp. 32073216.

[22] Taheri, B., Chalmers, D., Wilson, J., \& Arshed, N. Would you really recommend it? Antecedents of word-of-mouth in medical tourism. Tourism Management, Vol.83, 2021. pp.104-209.

[23] Webster Jr., F.E. \& Keller, K.L. A roadmap for branding in industrial markets, Journal of Brand Management, Vol.11, No.5, 2004, pp. 388-402.

[24] Keller, K. Conceptualizing, measuring, and managing customer-based brand equity, Journal of Marketing, Vol.57, No.1, 1993. pp. $1-22$.

[25] Anderson, E. W. Customer satisfaction and word of mouth. Journal of Service Research, Vol.1, No.1, 1998. pp. 5-17.

[26] Platis, C., Spanou, A., Messaropoulos, P., Kastanioti, C., \& Zoulias, E.A. Diabetic Patients' Quality of Life and their Relationship in Compliance with Antidiabetic Treatment. Case Study of Patients in a Public Hospital in Greece, WSEAS Transactions on Biology and Biomedicine, Vol. 17, 2020, pp. 32-38.

[27] Hair Jr, J. F., Hult, G. T. M., Ringle, C. M., \& Sarstedt, M. A primer on partial least squares structural equation modeling (PLS-SEM). Sage publications. 2021.

[28] Kash, B., \& McKahan, M. The evolution of measuring patient satisfaction. Journal of Primary Health Care and General Practice, Vol.1, No.1, 2017. pp. 1-4.

[29] Marley, K. A., Collier, D. A., \& Meyer Goldstein, S. The role of clinical and process quality in achieving patient satisfaction in hospitals. Decision Sciences, Vol.35, No.3, 2004. pp.349-369

[30] Rosenbusch, J., Ismail, I. R., \& Ringle, C. M. The agony of choice for medical tourists: a patient satisfaction index model. Journal of Hospitality and Tourism Technology. 2018.

[31] Bitner, M. J. Servicescapes: The impact of physical surroundings on customers and employees. Journal of Marketing, Vol.56, No.2, 1992. pp.57-71.
[32] Fang, F., Zhu, H., Li, X., \& Wei, H. Nurses' perceptions of caring: a directed content analysis based on the CARE model. International Journal for Human Caring, Vol.24, No.1, 2020. pp.50-58.

[33] Meesala, A., \& Paul, J. Service quality, consumer satisfaction and loyalty in hospitals: Thinking for the future. Journal of Retailing and Consumer Services, Vol.40, 2018. pp. 261-269.

[34] Chahal, H., \& Bala, M. Significant components of service brand equity in healthcare sector. International Journal of Health Care Quality Assurance. 2012.

[35] Maisam, S., \& Mahsa, R. D. Positive word of mouth marketing: Explaining the roles of value congruity and brand love. Journal of Competitiveness, Vol.8, No.1, 2016. pp. 1937.

[36] Hair, J. F., Risher, J. J., Sarstedt, M., \& Ringle, C. M. When to use and how to report the results of PLS-SEM. European Business Review. 2019

[37] Cohen, J. Set correlation and contingency tables. Applied psychological measurement, Vol.12, No.4, 1988. pp. 425434.

[38] Rapport, F., Hibbert, P., Baysari, M., Long, J. C., Seah, R., Zheng, W. Y., \& Braithwaite, J. What do patients really want? An in-depth examination of patient experience in four Australian hospitals. BMC Health Services Research, Vol.19, No.1, 2019. pp. 1-9.

[39] Al-Gharaibeh, O. B., \& Ariffin, A. A. M. The Influence of Brand Attitude on Behavioral Intention in the Context of National Carrier's Service Failure. GeoJournal of Tourism and Geosites, Vol.34, No.1, 2021. pp. 193-196.

\section{Contribution of Individual Authors to the Creation of a Scientific Article (Ghostwriting Policy)}

Ahmad Azmi M. Ariffin primarily involved in research instrument development.

Norhayati M.Zain and Bama V.V.Menon were the key persons for the data collection and interpretation.

Norzalita A. Aziz was mainly responsible for data analysis. 
Sources of Funding for Research Presented in a Scientific Article or Scientific Article Itself

This study was funded by KPJ Healthcare Berhad (GSB-2019-012).

Creative Commons Attribution License 4.0

(Attribution 4.0 International, CC BY 4.0)

This article is published under the terms of the Creative Commons Attribution License 4.0

https://creativecommons.org/licenses/by/4.0/deed.en US 